\title{
Surgical treatment of multiple ventricular septal defects using a biologic glue
}

The closure of multiple ventricular septal defects remains a surgical challenge. Mortality and morbidity are high. Left ventricular incision and multiple patches or stitches impair septal motion and function. We searched for a method that would cause minimal left ventricular and septal dysfunction. The use of fibrin seal for closing ventricular septal defects was considered. The method was first tested in animals so as to assess the internal resistance of the fibrin seal to stretching and fragmentation in addition to its adhesiveness and hence the absence of left-to-right embolization of the fibrin seal clot and the long-term success of the ventricular septal defect closure further to complete resorption of the ventricular septal defect clot. This experimental work was very satisfactory. Between April 1986 and September 1991, 15 children were operated on with the use of this technique. The overall hospital mortality rate was $6 \%$. There were no reoperations for residual ventricular septal defects. All the long-term survivors $(n=13)$ were in excellent clinical condition with no or trivial residual shunt attested by color flow mapping investigation. This experimental and clinical experience suggests that satisfactory results can be achieved with the use of fibrin seal for the closure of multiple muscular ventricular septal defects. (J Thorac Cardiovasc Surg 1994;107:96-102)

Francine Leca, MD, Joseph Karam, MD, Pascal R. Vouhe, MD, Wassim Khoury, MD, Daniel Tamisier, MD, Olivier Bical, MD, Eduardo Da Cruz, MD, and Michèle Thibert, Paris, France

$\mathrm{M}$ ultiple ventricular septal defects (VSDs), isolated or associated with other cardiac abnormalities, represent a severe pathologic condition for which a usual surgical repair proves to be difficult and dangerous. In the presence of "Swiss cheese" forms, postoperative morbidity and mortality remain high. This led us to search for a simple, efficient, and noninjurious technique of closing muscular VSDs with the use of a biologic glue.

Subsequent to experimental work in animals, clinical use began.

\section{Materials and methods}

Fibrin seal. Fibrin seal (FS) is of human origin (Tissucol, Immuno-France, Orly, France; Table I). It consists of concen-

From the Department of Cardiovascular Surgery, Laënnec Hospital, Paris, France.

Received for publication Oct. 22, 1992.

Accepted for publication March 18, 1993.

Address for reprints: Francine Leca, MD, Laënnec Hospital, Department of Cardiovascular Surgery, 42 rue de Sèvres, 75340 Paris Cédex 07, France.

Copyright $\odot 1994$ by Mosby-Year Book, Inc.

$0022-5223 / 94 \$ 1.00+.10 \quad 12 / 1 / 48791$
Table I. Composition of Tissucol

\begin{tabular}{lc}
\hline \multicolumn{1}{c}{ Component } & Concentration \\
\hline Fibrinogen & $70-110 \mathrm{mg} / \mathrm{ml}$ \\
Factor XIII & $10-50 \mathrm{U} / \mathrm{ml}{ }^{*}$ \\
Plasmafibronectin $(\mathrm{CIG})$ & $2-9 \mathrm{mg} / \mathrm{ml}$ \\
Plasminogen & $40-120 \mu \mathrm{g} / \mathrm{ml}$ \\
Aprotinin & $3000 \mathrm{KIU} / \mathrm{ml} \dagger$ \\
Thrombin & $500 \mathrm{IU} / \mathrm{ml} \ddagger$ \\
Calcium chloride & $40 \mathrm{mmol} / \mathrm{ml}$
\end{tabular}

*One unit (U) factor XIII is the activity contained in $1 \mathrm{ml}$ of fresh plasma. $\dagger$ Thirty kallikrein inhibitor units (KIU).

$\ddagger$ One International Unit (IU) of thrombin is defined as the activity contained in $0.0853 \mathrm{mg}$ of the first International Standard of Human Thrombin.

Table II. VSD creation

\begin{tabular}{cccc}
\hline $\begin{array}{c}\text { Sheep } \\
(\mathrm{n}=17)\end{array}$ & $\begin{array}{c}V S D_{S} \\
(\mathrm{n}=35)\end{array}$ & $\begin{array}{c}\text { Diameter } \\
(\mathrm{mm})\end{array}$ & Method \\
\hline 3 & 4 & 5 & AoP \\
3 & 8 & 5 & HP \\
6 & 13 & 6 & HP \\
2 & 7 & 7 & HP \\
3 & 3 & 10 & HP \\
\hline
\end{tabular}

$A o P$, Aortic punch; $H P$, hollow punch. 
Table III. Pressure gradient

\begin{tabular}{lccccc}
\hline & & \multicolumn{3}{c}{ Range } \\
\cline { 3 - 6 } & Mean & $S D$ & Min & Max & No. of sheep \\
\hline Before VSD creation & 98.2 & 13.6 & 80.0 & 115.0 & 5 \\
After VSD creation & 40.2 & 11.8 & 27.0 & 57.0 & 5 \\
After VSD closure & 58.8 & 15.7 & 38.0 & 72.0 & 5 \\
Catheterization on day 7 & 91.9 & 8.9 & 80.0 & 100.0 & 7 \\
\hline
\end{tabular}

Pressure gradient is between systolic FA and systolic RV pressures. All values are given in millimeters of mercury. SD, Standard deviation; Min, minimum; Max, maximum.

trated lyophilized fibrinogen enriched with factor XIII and fibronectin. An aprotinin solution warmed to $37^{\circ} \mathrm{C}$ was added to the fibrinogen. The mixture was stirred until complete dissolution. We used the Fibrinotherm $\mathbf{S}$ device (Immuno-Vienna, Vienna, Austria), a heating device with a thermostat and a magnetic agitator, to prepare the solutions. Lyophilized thrombin was dissolved in calcium chloride solution and maintained at $37^{\circ} \mathrm{C}$. Dissolved fibrinogen and dissolved thrombin were mixed only at the time of use because of very rapid clot formation, beginning after a few seconds and almost complete in 3 minutes. 1,2

\section{Experimental study}

Materials. We operated on 17 Hampshire sheep (weight range 40 to $60 \mathrm{~kg}$ ). Induction of general anesthesia before operation was done with pentobarbital, and anesthesia was maintained with halothane. A central venous pressure catheter was introduced through the external jugular vein by percutaneous puncture. An arterial blood pressure catheter was put in the left femoral artery (FA). Arterial blood pressure and central venous pressure were monitored continuously.

A right thoracotomy through the fifth intercostal space allowed satisfactory exposure. Two cannulas were introduced in the venae cavae. The arterial cannula was in the right FA. Cardiopulmonary bypass (CPB) was done with a bubble oxygenator and total hemodilution. Each VSD was created by multiple bites of the septum with a $4 \mathrm{~mm}$ aortic punch in the first three sheep. We used a hollow metallic punch with a sharp cutting end that had various diameters to remove a muscular core from the septum in the remaining 14 sheep.

In the first five sheep the right ventricle (RV) was closed after VSD creation, the CPB interrupted, the cannulas left in situ, and the following measurements done: RV pressure, pulmonary artery (PA) pressure, blood oxygen saturation from the FA, right auricle, and PA. Left-to-right shunt was calculated as the pulmonary/systemic flow ratio with the following method: blood oxygen saturation of FA-right auricle/FA-PA. CPB was then restarted and the RV was reopened. Closure of the VSDs was performed. In the remaining 12 sheep, one period of CPB was used and the VSDs were closed immediately after creation.

We closed the VSDs with FS of human origin (Tissucol): the aorta was clamped, the created VSDs were kept blood-free, and the mixture of fibrinogen and thrombin was injected with use of the Duploject System ${ }^{3}$ (Immuno-Vienna) for simultaneous mixing and injection of both solutions. After a few seconds, a whitish gel appeared as a result of polymerization of fibrin. The aortic clamp was released 3 minutes later, after removal of air from the left side of the heart. Total normothermic aortic clamping with a beating heart had to be less than 5 minutes in duration, to minimize ischemic insult to the normothermic
Table IV. Causes of death

\begin{tabular}{cl}
\hline & \multicolumn{1}{c}{ Cause of death } \\
\hline $\begin{array}{c}\text { Control sheep (10 } \\
\text { mm VSD } \\
\text { without FS) }\end{array}$ & Acute pulmonary edema \\
Sheep receiving & \\
FS & Hypoxia, pneumothorax, and \\
& atrioventricular block \\
& Iatrogenic mitral insufficiency \\
& Systemic air embolism \\
& Septicemia \\
& CPB problems \\
& Unexplained death 40 hours after \\
& operation
\end{tabular}

myocardium. The RV was closed, and the sheep weaned from CPB. Pressure measurements, blood oxygen saturation, and blood gas levels were determined, the right lung inflated, the thoracotomy closed, and a thoracic drainage system installed.

Postoperative care had to be minimal and of short duration. Medical care could not exceed 5 to 6 hours. This implied rapid detubation and total sheep autonomy.

Catheterization with a 7F Swan-Ganz catheter (Baxter Healthcare Corporation, Edwards Division, Irvine, Calif.) was done on the seventh postoperative day in seven sheep: pressure measurements and staged blood oxygen saturation measurements were taken to detect early VSD opening. The hearts of the surviving sheep were examined macroscopically and preserved in a $5 \%$ formalin solution for microscopic study after the sheep were killed 19 to 122 days after operation.

All sheep received humane care in compliance with the "Principles of Laboratory Animal Care" formulated by the National Society for Medical Research and the "Guide for the Care and Use of Laboratory Animals" prepared by the National Academy of Sciences and published by National Institutes of Health (NIH Publications No. 80-23, revised 1978).

Results. Table II shows the distribution of the 35 VSDs created in the 17 sheep of the experiment.

Gradient between systolic FA pressure and systolic RV pressure (FA pressure - RV pressure) was calculated in the first five sheep. Results are given in Table III. After creation of the VSDs a decrease in the FA pressure-RV pressure gradient was found. The FA pressure-RV pressure gradient increased immediately after closure of the VSDs but not to initial values; the PA and RV pressures were high immediately after $\mathrm{CPB}$. On the seventh day, postoperative catheterization showed preoperative values of FA pressure-RV pressure gradient.

Left-to-right shunting appeared immediately after creation 


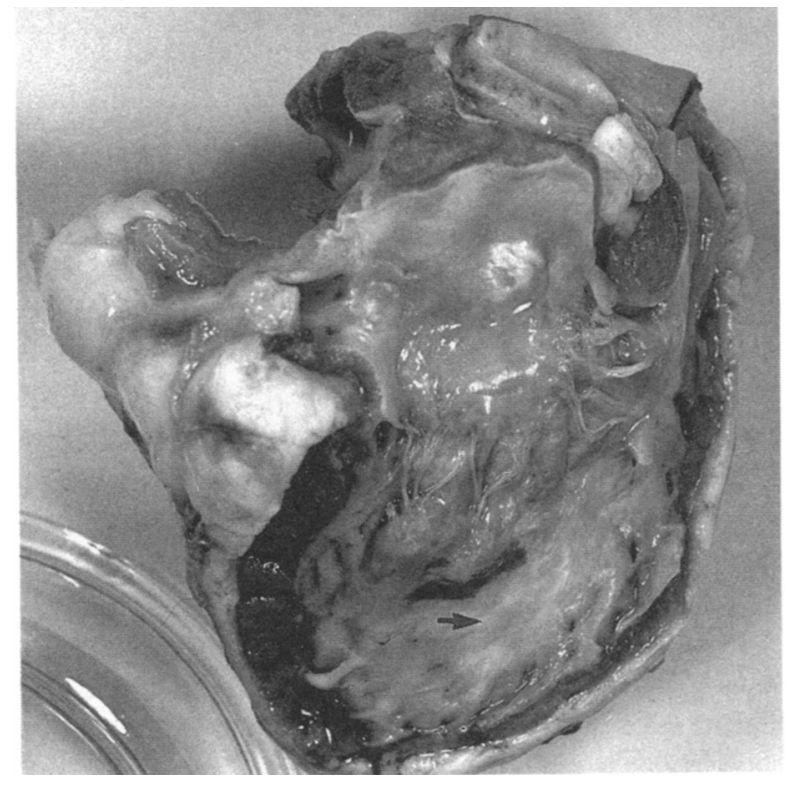

Fig. 1. Right ventricular wall of sheep heart has been removed. Macroscopic aspect of closed VSD: whitish scar on septum (arrow).

of VSDs: pulmonary/systemic flow ratio increased from 1.0 to $1.5 \pm 0.2$ (range 1.3 to 1.6 ) and returned to its initial value immediately after closure. The catheterization on the seventh postoperative day in the seven studied sheep did not show any left-to-right shunting.

A $10 \mathrm{~mm}$ VSD in one sheep was not closed by FS, to serve as a control. This sheep died after 5 hours with acute pulmonary edema.

The causes of early death are given in Table IV. The sheep died within 1 to 48 hours. The hearts of the seven sheep with early deaths ( 13 VSDs) were removed for macroscopic examination. Only five (eight VSDs) were studied microscopically; one was lost and one injured during removal and was discarded.

The results of macroscopic study of the hearts from sheep that died early are given in Table V. FS was present in all the VSDs examined. There was no FS embolization in the coronary arteries. Closure of 11 of 12 VSDs was certain and was doubtful in one VSD in sheep 7 in which the heart was injured on removal. In sheep 8, direct heart massage lasting 30 minutes, because of ventricular fibrillation, did not move the FS clot out of the VSD, which remained completely closed. On microscopic examination some polynuclear leukocytes, macrophages, and giant cells were present in the myocardium surrounding the FS only in one VSD. Hematoma of the septal myocardium was present in the four VSDs of the first three sheep in which the aortic punch technique was used. The FS was cell-free in all sheep in the early death group.

Table VI shows the results of macroscopic and microscopic study of 12 VSDs in six sheep 19 to 53 days after operation: endocardium covered the VSD orifice on both sides of the septum (Fig. 1) in 11 VSDs. One VSD in sheep 13 was not closed. The two VSDs of sheep 13 had been closed with a slow-clotting FS (30 minutes). On microscopic study, among the 11 closed

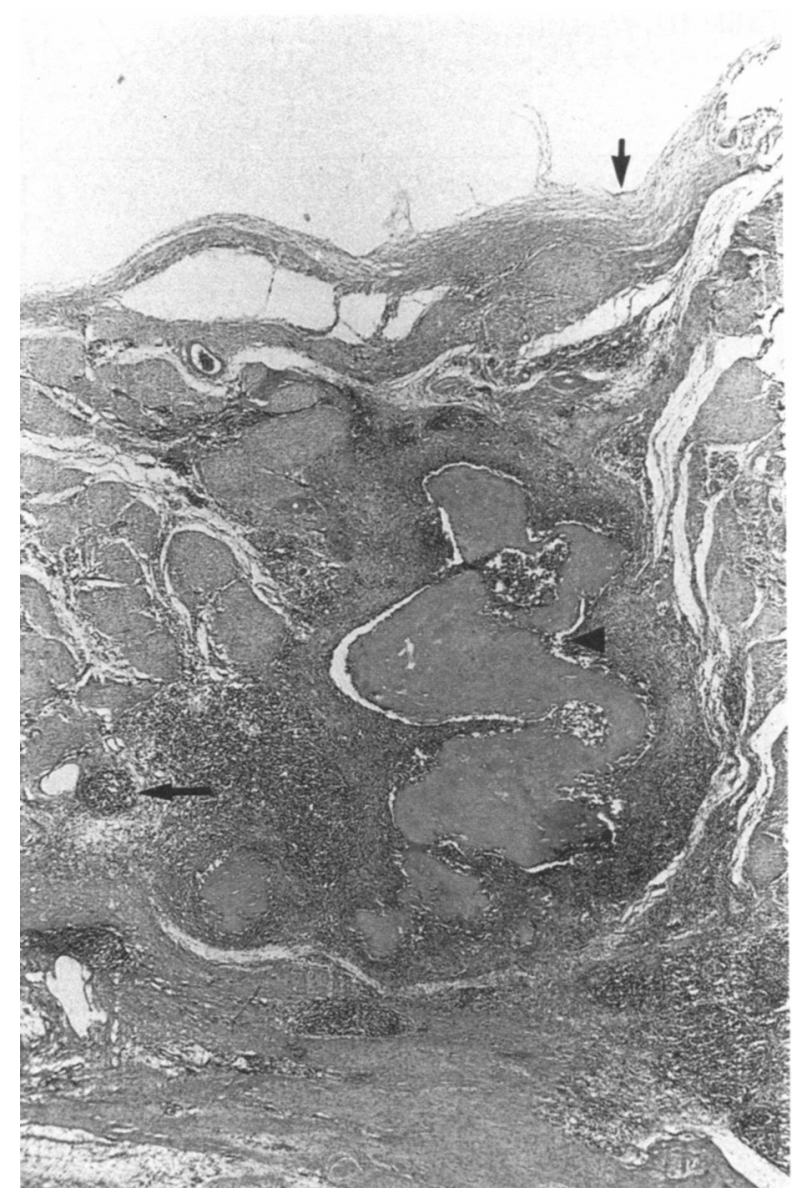

Fig. 2. FS residue (arrowhead) surrounded by inflammatory cells with some lymphoid aggregates (arrow pointing left). Arrow pointing down indicates endocardium. (Original magnification $\times 5$.)

VSDs, FS residue was found in 5. Inflammation was present in 11 VSDs consisting of plasmocytes and lymphocytes (Fig. 2) gathered in lymphoid nodules in certain areas. Scar consisted of fibrous tissue (Fig. 3) with dystrophic adipose tissue in six VSDs. This tissue filled the VSD holes.

Table VII shows the results of macroscopic and microscopic study of 10 VSDs in four sheep after 73 to 122 days. All the VSDs were completely closed and covered with endocardium on both sides of the septum. There was no FS residue. Inflammation was present in 7 of 10 VSDs. All the VSDs were filled with fibrous and adipose tissue.

\section{Clinical study}

Population. Between April 1986 and September 1991, 15 patients aged from 1 month to 6 years (mean 18.3 months) underwent operation for multiple VSDs in Laënnec Hospital.

Eight patients $(53.3 \%)$ had multiple VSDs without any other malformation. The other seven patients $(46.7 \%)$, who also had muscular VSDs, showed associated malformations (Table VIII): transposition of the great arteries $(n=1 ; 6.7 \%)$; complete atrioventricular canal $(n=1 ; 6.7 \%)$; aortic coarctation $(n=2$; 
Table V. Macroscopic study in early death sheep $(\mathrm{n}=7)$

\begin{tabular}{|c|c|c|c|c|c|}
\hline \multirow[b]{2}{*}{ Sheep no. } & \multirow[b]{2}{*}{$\begin{array}{c}\text { Survival } \\
\text { (hr) }\end{array}$} & \multirow[b]{2}{*}{$\begin{array}{c}\text { No. of } \\
\text { VSDS }\end{array}$} & \multirow[b]{2}{*}{$\begin{array}{c}\text { Diameter } \\
(\mathrm{mm})\end{array}$} & \multicolumn{2}{|c|}{ Macroscopy } \\
\hline & & & & $\begin{array}{c}\text { Closure of } \\
\text { VSDS }\end{array}$ & $\begin{array}{c}\text { Presence } \\
\text { of FS }\end{array}$ \\
\hline \multirow[t]{2}{*}{1} & 6 & 2 & 5 & + & + \\
\hline & & & 5 & + & + \\
\hline 2 & 24 & 1 & 5 & + & + \\
\hline 3 & 5 & 1 & 5 & + & + \\
\hline \multirow[t]{3}{*}{7} & 40 & 3 & 5 & $?$ & + \\
\hline & & & 5 & + & + \\
\hline & & & 5 & + & + \\
\hline \multirow[t]{3}{*}{12} & 48 & 3 & 6 & + & + \\
\hline & & & 6 & + & + \\
\hline & & & 6 & + & + \\
\hline \multirow[t]{2}{*}{8} & 1 & 2 & 7 & + & + \\
\hline & & & 7 & + & + \\
\hline 17 & 5 & 1 & 10 & 0 & 0 \\
\hline
\end{tabular}

The sheep number is the number given in the experiment. Survival is the number of hours from the injection of FS in the created VSDs to death. The total number of created VSDs in this group was 13. The question mark means doubtful macroscopic closure of VSD in sheep 7 . Sheep 17 was a control that did not receive FS.

Table VI. Macroscopic and microscopic study: 19 to 53 days survival $(\mathrm{n}=6)$

\begin{tabular}{|c|c|c|c|c|c|c|c|c|c|}
\hline \multirow[b]{2}{*}{$\begin{array}{c}\text { Sheep } \\
\text { no. }\end{array}$} & \multirow[b]{2}{*}{$\begin{array}{c}\text { Survival } \\
\text { (day) }\end{array}$} & \multirow[b]{2}{*}{$\begin{array}{l}\text { No. of } \\
\text { VSDs }\end{array}$} & \multirow[b]{2}{*}{$\begin{array}{c}\text { Diameter } \\
(\mathrm{mm})\end{array}$} & \multirow{2}{*}{$\begin{array}{c}\text { Macroscopy } \\
\text { Closure } \\
\text { of VSDs }\end{array}$} & \multicolumn{5}{|c|}{ Microscopy } \\
\hline & & & & & Endocardium & $\begin{array}{l}\text { Residue } \\
\text { of FS }\end{array}$ & Inflammation & Fibrosis & Adipocytes \\
\hline \multirow[t]{3}{*}{5} & 19 & 3 & 5 & + & + & 0 & + & + & + \\
\hline & & & 5 & + & + & 0 & + & + & + \\
\hline & & & 5 & + & + & 0 & + & + & + \\
\hline \multirow[t]{2}{*}{4} & 39 & 2 & 5 & + & + & 0 & + & + & 0 \\
\hline & & & 5 & + & + & + & + & + & + \\
\hline \multirow[t]{2}{*}{13} & 30 & 2 & 6 & + & + & 0 & + & + & 0 \\
\hline & & & 6 & 0 & 0 & 0 & + & 0 & 0 \\
\hline \multirow[t]{3}{*}{14} & 42 & 3 & 6 & + & + & + & + & + & 0 \\
\hline & & & 6 & + & + & + & + & + & 0 \\
\hline & & & 6 & + & + & + & + & + & 0 \\
\hline 15 & 53 & 1 & 10 & + & + & 0 & 0 & + & + \\
\hline 16 & 52 & 1 & 10 & + & + & + & + & + & + \\
\hline
\end{tabular}

$13.3 \%)$; tetralogy of Fallot $(n=2 ; 13.3 \%)$; and double-outlet right ventricle $(n=1 ; 6.7 \%)$.

NUMBER AND LOCALIZATION OF THE MULTIPLE VSDS. All patients had a large VSD (100\%): 12 were perimembranous $(80 \%), 2$ were in the trabecular septum $(13 \%)$, and 1 was in the inlet septum. Beside this large VSD, all patients had two or more localized muscular VSDs. Five children had one or two infundibular VSDs below the pulmonary valve. Eight children had uncountable multiple VSDs, a condition known as "Swiss cheese."

Eleven patients underwent a preoperative catheterization and angiography. All were studied with echo-Doppler ultrasonography. Diagnosis was achieved with catheterization in $9(80 \%)$ out of 11 cases and with echocardiography in $8(53.3 \%)$ of 15 cases. Color Doppler ultrasonography was used in five patients.

Six patients $(40 \%)$ underwent a prior palliative intervention: PA banding in four and coarctation repair in two.

In 15 instances, the operative approach for VSD repair was achieved through the right atrium $(100 \%)$. In two cases a right ventriculotomy was associated $(13 \%$, in two cases of tetralogy of Fallot), once through the pulmonary valve $(6 \%)$. There were no left ventriculotomies.

All the large interventricular septum defects were closed with either a pericardial patch or a pericardial patch lined with Dacron fabric.

The infundibular VSDs were closed by one or two pledgetsupported sutures (four cases) or only by FS (1 case).

Some medium muscular VSDs were also closed by pledgetsupported sutures when their margins were clearly identified. Apical muscular VSDs $(53.3 \%)$ were closed only by FS injection. All patients had one or more small muscular VSDs closed by FS.

The VSD margins were not systematically deepened: the needle was driven in through the VSD until the left ventricle was entered and then carefully withdrawn while the FS was injected. The operating field must be dry. The setting of the glue is 
Table VII. Macroscopic and microscopic study: 73 to 122 days survival $(\mathrm{n}=4)$

\begin{tabular}{|c|c|c|c|c|c|c|c|c|c|}
\hline \multirow[b]{2}{*}{$\begin{array}{c}\text { Sheep } \\
\text { no. }\end{array}$} & \multirow[b]{2}{*}{$\begin{array}{c}\text { Survival } \\
\text { (day) }\end{array}$} & \multirow[b]{2}{*}{$\begin{array}{l}\text { No. of } \\
\text { VSDS }\end{array}$} & \multirow[b]{2}{*}{$\begin{array}{c}\text { Diameter } \\
(\mathrm{mm})\end{array}$} & \multirow{2}{*}{$\begin{array}{c}\text { Macroscopy } \\
\text { Closure of } \\
\text { VSDs }\end{array}$} & \multicolumn{5}{|c|}{ Microscopy } \\
\hline & & & & & Endocardium & $\begin{array}{c}\text { Residue } \\
\text { of FS }\end{array}$ & Inflammation & Fibrosis & Adipocytes \\
\hline \multirow[t]{3}{*}{10} & 116 & 3 & 6 & + & + & 0 & + & + & + \\
\hline & & & 6 & + & + & 0 & + & + & + \\
\hline & & & 6 & + & + & 0 & + & + & + \\
\hline \multirow[t]{2}{*}{11} & 101 & 2 & 6 & + & + & 0 & + & + & + \\
\hline & & & 6 & + & + & 0 & + & + & + \\
\hline \multirow[t]{3}{*}{6} & 73 & 3 & 7 & + & + & 0 & 0 & + & + \\
\hline & & & 7 & + & + & 0 & + & + & + \\
\hline & & & 7 & + & + & 0 & + & + & + \\
\hline \multirow[t]{2}{*}{9} & 122 & 2 & 7 & + & + & 0 & 0 & + & + \\
\hline & & & 7 & + & + & 0 & 0 & + & + \\
\hline
\end{tabular}

very fast. The injection is done slowly enough that the glue sets before it can drip into the left ventricle. It is important to avoid too deep an insertion into the VSD toward the left ventricle.

\section{Results}

Mortality. The overall hospital mortality rate was $6 \%$. One child died on day 2 as a result of a "stone heart" syndrome that had appeared in the right side of the heart at the end of the operation.

Morbidity. One child had a postoperative transient hemiplegia that resolved completely. This event was most likely the result of a small FS fragment embolism from the left ventricle. This hypothesis was not confirmed, but remains likely. During postoperative echocardiography in another patient, a small "bell" attached to the left side of the septum was noted. This remained stable during further examinations. A patient with tetralogy of Fallot had a grade III atrioventricular block that required insertion of a pacemaker 3 months after the complete repair.

Follow-up. Clinical and echocardiographic follow-up was done on all patients during a period of 3 months to 3 years. One child died at month 7 . This patient had a severe atrioventricular canal defect, which had been repaired, but a persistent and severe mitral regurgitation developed that caused heart failure; cardiac arrest occurred during a follow-up catheterization. This catheterization had demonstrated the ventricular septum to be intact.

Reoperation for VSD closure. There were no reoperations for residual VSD.

The clinical evolution of the 13 survivors was excellent: signs of heart failure, shunt, and pulmonary hypertension have disappeared. The somatic growth curves have normalized. Postoperative color Doppler echocardiograms showeda perfectly tight interventricular septum in $8(61.5 \%)$ of 13 surviving patients. The other 5 patients (including 4 among the 8 "Swiss cheese" cases) show "micro" VSDs perceptible only on the color Doppler echocardiograms and without any hemodynamic effect on echographic study.

\section{Discussion}

The prevalence of multiple VSDs is low, occurring in $12 \%$ of the patients with VSD only and in $2 \%$ of those with
VSD and transposition of the great arteries, tetralogy of Fallot, or atrioventricular canal. ${ }^{4}$ The diagnosis of multiple VSDs has greatly benefited from recent color flow imaging techniques. ${ }^{5}$

The surgical closing of multiple VSDs remains difficult with uncertain results, especially in the "Swiss cheese" forms. Whenever possible, a right-sided approach through the right atrium or a right ventriculotomy is used. Detaching the lower end of the septal band allows some muscular VSDs to be clearly defined and closed. ${ }^{6}$ When the VSDs are considered to be too numerous to be individually closed, two techniques have been used: interrupted mattress sutures are placed in the anterior wall along the left anterior descending coronary artery and pledgets placed inside the right ventricle below the VSDs to compress the VSDs. ${ }^{7}$ A left ventriculotomy approach can also be used; it may be necessary to place a patch over the entire muscular septum. The exposure from the left side is excellent but this approach can lead to important ventricular dysfunction and high rate of reoperation. 4, 9-12

Before clinical use of FS the following questions had to be answered: Will this fibrin glue set quickly enough to achieve an instant "plug?" Will its adhesiveness be sufficient to avoid embolism? Will the VSD remain closed subsequent to glue resorption? The first step of the investigative work was to create a laboratory model. In 17 lambs 35 VSDs of 5 to $10 \mathrm{~mm}$ in diameter were made and then closed with FS. This study allowed us to conclude that the technique was safe (no complications or side effects, no glue embolism), efficient (no residual VSD in $95.5 \%$ of the cases), and easy to use. We noticed under microscopic study a fibroblast migration from the VSD walls into the FS and a rapid endothelialization of both sides of the fibrin clot.

Closure of these muscular VSDs was successful in all 
Table VIII. Associated cardiopathies

\begin{tabular}{lcc}
\hline Malformation & $\begin{array}{c}\text { No. of } \\
\text { patients }\end{array}$ & $\%$ \\
\hline VSDs only & 8 & 53.3 \\
TGA-VSD & 1 & 6.7 \\
AVC & 1 & 6.7 \\
CoA & 2 & 13.3 \\
TF & 2 & 13.3 \\
DORV & 1 & 6.7
\end{tabular}

$T G A$, Transposition of the great arteries; $A V C$, common atrioventricular canal; $C O A$, coarctation of the aorta: $T F$, tetralogy of Fallot; $D O R V$, double-outlet right ventricle.

cases in which fast-clotting FS was used. In one sheep (No. 13) an unclosed VSD was the result of accidental use of slow-clotting FS with a low concentration thrombin of $4 \mathrm{IU} / \mathrm{ml}$ instead of $500 \mathrm{IU} / \mathrm{ml}$. The total clotting time of this FS was 30 minutes versus 3 minutes for the fast-clotting FS.

To simplify the procedure we closed the VSD under normothermia. Moderate hypothermia and cardioplegic arrest were not used in the experimental study, but FS can be used in these conditions because it was done for hemostatic purposes. ${ }^{14}$

FS was safe experimentally: no deaths could be attributed to the glue or its embolization. Only one control sheep had a $10 \mathrm{~mm}$ VSD left open: death occurred in 5 hours from pulmonary edema. No other control sheep without FS were included in the study and we have no data about spontaneous closure of the surgically created VSDs.

Encouraged by these experimental results, we used this technique in 15 patients who had multiple VSDs.

Neither of the two deaths that occurred in this group appeared to be ascribable to the technique: in one instance the surgeon noticed at the beginning of the operation an abnormally thick and hypokinetic right ventricle. Death occurred on day 2 in a context of an isolated right-sided failure without any effect to either the left ventricle or the septum. Unfortunately the coronary arteries were not examined, but clinical signs and evolution (electrocardiogram, enzyme studies) did not call to mind a coronary embolism. The pulmonary biopsy did not reveal any severe arteriolar lesion. All the VSDs were well closed. The second death occurred late associated with severe mitral regurgitation after repair of an atrioventricular canal defect.

FS proved its efficiency in all patients. All the controlled septums are perfectly tight ( 10 cases) or present residual microscopic VSDs (5 cases).

From a technical point of view, the use of FS facilitates

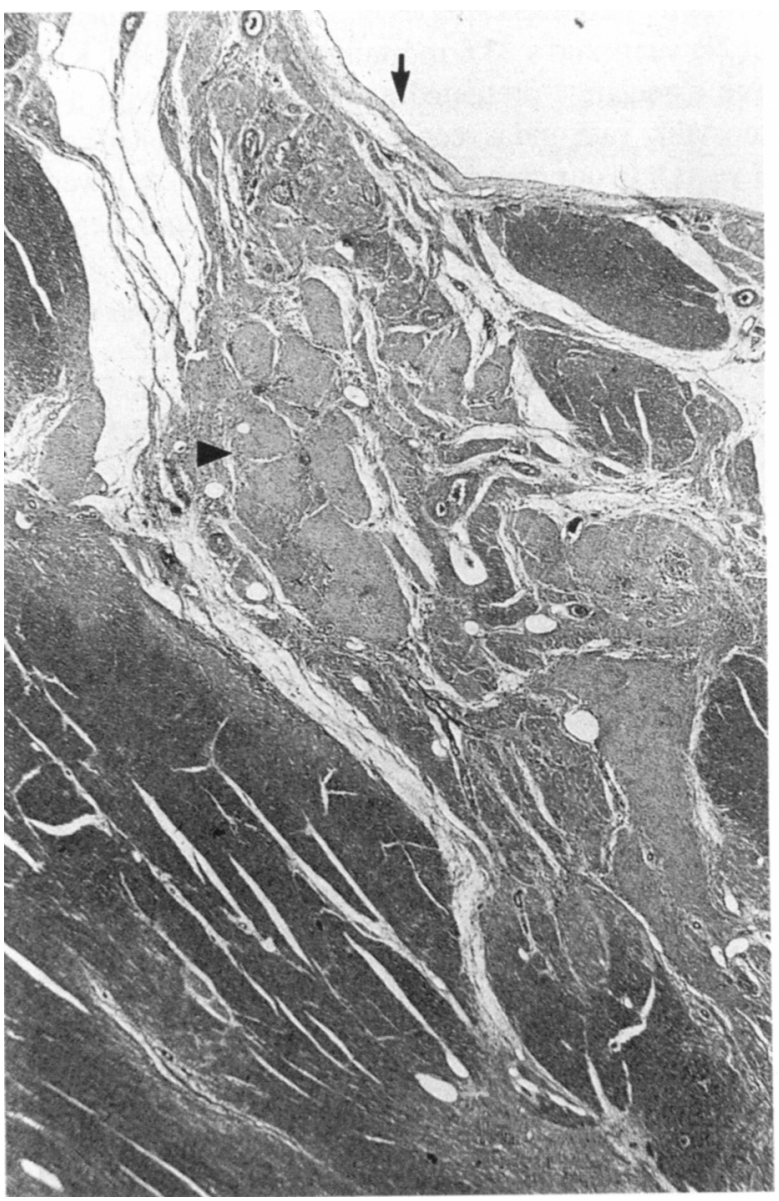

Fig. 3. Fibrous tissue (arrowhead) filling VSD hole; endocardium (arrow) covering scar. No FS residue. (Original magnification $\times 5$.)

repair: after closure of the main VSD with a patch, injection of a physiologic solution into the left ventricle while the aorta and pulmonary artery are clamped reveals the VSDs, which are then located by a dissector. The operating field is well dried and the syringe needle containing the biologic glue is driven into the VSD toward the left ventricle. As the needle is carefully withdrawn, the glue is injected. The sole delicate gesture is to avoid too deep an insertion inside the left ventricle so as not to create an intracavitary left ventricular glue ball attached to the septum, which could result in embolism.

The 3-year follow-up for some children confirms that the repair remains intact after glue resorption; this had been suggested by the experimental study.

The use of FS for closing VSDs seems to be an easy and reliable technique and has been associated with improved results in this difficult patient group. Between 1978 and 
1982, we published a series of 37 cases with a mean age of $2^{1 / 2}$ years and a $38 \%$ mortality rate. ${ }^{13}$ In 1980, Kirklin and associates ${ }^{4}$ presented a 29 -case series with a $14 \%$ mortality rate and a reoperation rate of $28 \%$ (mean age 3 years). In our current series, the mean age is lower (18 months), the hospital mortality rate is $6 \%$, and there is no reoperation.

Our protocol now for operations for multiple VSDs is as follows:

1. Color flow mapping is consistently used for the preoperative diagnosis, keeping in mind that its reliability does not exceed $80 \%$.

2. Indications for first intention repair continue to broaden in young children, even in cases of associated complex cardiopathies.

3. During the operation, exposure of the ventricular septum is achieved by a wide right atriotomy through the tricuspid valve. After closure of the large VSD with a patch, pressurized saline solution is injected into the left ventricle via the mitral valve to detect residual muscular VSDs.

4. These VSDs are closed by pledget-supported sutures if the VSD is large ( 8 to $10 \mathrm{~mm}$ ) with clearly observed rims or with FS if the VSD is muscular and small.

5. Repeated saline injections are done until complete repair has been obtained. After CPB the absence of residual shunt is demonstrated by blood-gas analysis. Echocardiographic color flow mapping is done in the intensive care unit.

We thank André Khayat from the Cardiac Surgery Department of Caen Hospital for the authorization to include one of his patients.

\section{REFERENCES}

1. Redl H, Schlag G. Fibrin sealant and its modes of application. In: Schlag G, Redl H, eds. Fibrin sealant in operative medicine. Berlin and Heidelberg: Springer-Verlag, 1986: 13-26.
2. Bagot-D'Arc M. La colle de fibrine en chirurgie: principe, indications actuelles et perspectives. Cah Chir 1986;57: 35-8.

3. Seelich T. Tissucol (Immuno Vienna): biochemistry and methods of application. J Head Neck Pathol 1982;3:65-9.

4. Kirklin J, Castaneda A, Keane J, Fellows K, Norwood W. Surgical management of multiple ventricular septal defects. J THORAC CaRdiovasC SURG 1980;80:485-93.

5. Sutherland GR, Smyllie JH, Ogilvie BC, Keeton BR. Colour flow imaging in the diagnosis of multiple ventricular septal defects. Br Heart J 1989;62:43-9.

6. Lincoln C, Jamieson S, Joseph M, Shinebourne E, Anderson RH. Transatrial repair of ventricular septal defects with reference to their anatomic classification. J THORAC CARDIOVASC SURG 1977;74:183-90.

7. Breckenridge IM, Stark J, Waterston DJ, Bonham Carter RE: Multiple ventricular septal defects. Ann Thorac Surg 1972;13:128-36.

8. Waldhausen JA, Herendeen T, Taybi $H$. Left ventriculotomy: effects on ventricular function and coronary vessels. Surgery 1964;56:868-73.

9. Singh AK, de Leval MR, Stark J. Left ventriculotomy for closure of muscular ventricular septal defects: treatment of choice. Ann Surg 1977;186:577-80.

10. Zavanella C, Matsuda H, Jara F, Subramanian S. Left ventricular approach to multiple ventricular septal defects. Ann Thorac Surg 1977;24:537-43.

11. Griffiths SP, Turi GK, Ellis K, et al. Muscular ventricular septal defects repaired with left ventriculotomy. Am J Cardiol 1981;48:877-86.

12. Fox KM, Patel RG, Taylor JFN, Stark J, de Leval MR, Macartney FJ. Multiple and single ventricular septal defect: a clinical and haemodynamic comparison. Br Heart J 1978;40:141-6.

13. Leca F, Tran Viet T, Borie H, et al. Traitement chirurgical des communications interventriculaires multiples. Ann Chir 1984;38:125-30.

14. Stark J, de Leval M. Experience with fibrin seal (Tisseel) in operations for congenital heart defects. Ann Thorac Surg 1984;38:411-3. 